\title{
PEQUENA NOTA
}

\section{a "CANTHUS" DE MARTIALIS}

\section{ARLINDO DE SOUSA}

O texto, em que nos apoiamos, é o seguinte epigrama, de dois versos: "Inducenda rota est: das nobis utile munus. | Iste trochus pueris, at mihi canthus erit" (XIV, 168; ou outros números, conforme as ediçōes) Aulus Persius Flaccus $(34-62$ ?, p. C.), outro poeta satírico, grave como Lucílio, a quem desejou imitar, e cáustico como Marcial diz "Nam quamvis prope te, quamvis, temone sub uno | Vertentem sese frustra sectabere canthum, | Cum rota posterior curras, et in axe secunda" (Satirae Persii, V, vv. $70-72$, ed. de N. - L. Achaintre, com o título Satires de Perse traduites en français par Sélis... Paris, 1822, pág. 220). Temo, onis é a "cabeçalha" ou "cabeçalho" do carro; canthus é a "camba" mas o termo é tomado no sentido geral trópico de "carro". Persius foi contemporâneo dos espanhóis Lucano e Séneca. Com êles conviveu e deles recebeu, certamente, informaçōes concernentes aos falares hispânicos. Quintiliano disse bem: “... quamquam eo, tamquam recepto, utiur Persius" (De Institutione Oratoria I, 5). O nosso "recebeu" está, pois, em relaçāo com o "recepto" do autor da de institutione oratoria e procura ser bem expressivo. $\mathrm{E}$ é a respeito de canthus que Quintiliano escreve as palavras acima, considerando o termo africano ou hispano, e introduzido no latim: “... si quis Afrum vel Hispanum latinae orationi nomen inserat, ut ferrum, quo rotae vinciuntur, dici solet canthus; quanquam eo, tamquam recepto, utitur Persius" (op. cit., ibid.) Tradução: “... se alguém insere na língua latina um nome africano ou hispânico, como, por exemplo, canthus, ferro por meio do qual as rodas são ligadas, de que, como vocábulo recebido, Pérsio usa".

Observe-se, pois, canthus, empregado por dois espanhóis, Marcial e Quintiliano, e pelo toscano Pérseo, que muito deveu à amizade e cultura lingüística hispana de outros dois espanhóis, Lucano e Séneca. O próprio cognome, Séneca, de velhos estratos indoeuropeus, deveria ter preocupado, sobremaneira, o poeta das Satirae. Vêde o magnífico trabalho de Antonio Tovar, Estudos sôbre las Primitivas Lenguas Hispánicas, Buenos Aires, 1949, capitulo Sôbre la Estirpe de Séneca, págs. 148 - 153. Inclinam-se 
para a origem gaulesa de canthus, Georges Dottin, La Langue Gauloise... Paris 1920; Ernout et Meillet, Dictionaire Etymologique de la Langue Latine. Histoire des Mots... Paris 1939; Augusto Magne, Dicionário Etimológico da Língua Latina, Rio de Janeiro, 1953, III, s, v. pág. 56. Trabalho simpático é aindä o de José Pedro Machado, Elementos Hispânicos do Vocabulário Latino, na Revista Lusitana, vol. XXXVIII, págs. 247 - 267 (Anos de 1940 - 43), de que saiu separata. O Pe. Augusto Magne poderia ter visto aí outros derivados portuguêses de canthus, v. g. cantrelas, em Trásos-Montes e cantelas, no Minho, "carro de rodas", assim como uma fonta do francês achanter, Péau Gatineau (Vie de S. Martin, p. 102).

Ainda como muito humilde adenda ao precioso estudo do Pe. Augusto Magne, v. Canthus ou Cantus, damos o que escrevemos na primeira parte das nossas OPRTP ( $=$ Origens Pre-Romanas da Toponimia Portuguesa), inéditas: Cantadoira ou cantadoura, canteiro, encanteirar, etc.. Cantadoira ou cantadoura: "peça do carro de bois, do chedeiro, onde encaixam duas bonecas ou bunecas, ainda dito bonecras ou bunecras, e penetram quatro cocões ou coucōes que seguram o eixo", em Amarante, Espinho, Feira, Gaia e Marco de Canaveses, conforme informações que obtivemos, em respostas a inquéritos lingüísticos, entre 1940 e 1945 . Em Monção, a cantadoira tem o nome de cacoeira, de calx - calc - , segundo supomos, e o sufixo - oira. Canteiro: "cavalete ou estrado de madeira, duas traves compridas onde pousam as pipas nas lojas ( $=$ adegas) ou adegas, e que sāo impedidas de rolar por quatro calços, da mesma origem etimológica de cocões ou coucões, o latim calx - calc-. Cocões ou coucões relacionam-se com a cantadoira, como os calços se relacionam com os canteiros das pipas. Encanteirar é "colocar as pipas nos canteiros, em Barcelos, Braga, Espinho, Feira e Gaia, pelo menos, e "colocar o barco sôbre varas e rolos de madeira na praia", em Espinho. Tiramos cantadoira ou cantadoura, canteiro e encanteirar sempre com a necessária dúvida metódica, científica, de canthus "ferro que envolve a roda do carro de bois", "ferro de corrume", "roda". o povo lavrador acha que o nome cantadoira ou cantadoura provém de o carro cantar. É uma etimologia popular. 0 que faz cantar o carro é o eixo e as bonecras. Também, se diz que o primeiro piolho, encontrado na cabeça de uma criança, deve ser morto no fundo de um cântaro oư cântara, a fim de que a criança saia cantadeira (informação preciosíssima de caráter folclórico, sociológico e lingüístico). É outra etimologia de índole popular e anticientífica. Na toponímia atual há: Cantada, Cantais, Cantanhede, Cantazinhas, Canteiro, Canteiros, Cantelães, Cantim, Cantinhas, Cantinho, Cantinhos, Canto, Cantonha, Cantos, Cantudo, Recantes, etc.. Na toponimia medieval, encontramos: Cantelaes, ano de 1220 (Inquisitiones, 146), Cantelaos ou Camtelaos - Cãtelaos, século XVI (no Arquivo Histórico Português, vol. VII pág. 277, texto do recenseamento ordenado por D. João III, em 1527, no título Demarquaçam da comarqua de Trallos Montes). É possível que, 
pelo menos, alguns dêstes topônimos provenha de canthus, se não provierem todos. O latim rotundus, de sentido aproximado, deu grande número de povoaçōes e sítios (Vêde os meus ELTP = Elementos Latinos da Toponímia Portuguesa, a sair; Úmica - Regiāo do Município da Feira, Aveiro 1954; Estudos de Lingua Portuguêsa... Rio de Janeiro, 1956). Cf. o grego Strongyle Stroggyle, ilha Grossa, atualmente (Rufus Festus Avienus, Ora Maritima, v. 453, ed. de Adolf Schulten, Fontes Hispaniae Antiquae, I). José Leite de Vasconcelos falou, a propósito de Cantinus, antropônimo, duma voz Cant. "brilhante, branco": "Cantinus... très repété dans le monde celtique, et que peut-être se décompose ainsi: Cant iu - s = Cant - io - s, du th. canto-, "brillant" "blane" (Opúsculos V, pág. 76). Há, pois, que ter em consideração não só canthus, mas também esta outra voz cant-. Com o mesmo étimo canthus relacionou W. Meyer Lübke, (REW, 1616), canto "ângulo", "esquina", "pedra grande para esquadria". De igual modo F. Adolfo Coelho, com apoio no grego chanthos, "canto do olho" (Dicionário Manual Etimológico da Língua Portuguêsa...). A.A. Cortesāo ligou canthus a um celta Kant (Subsídios para um Dicionário Completo (Histórico-Etimológico) da Língua Portuguêsa, Coimbra, 1900), possìvelmente o mesmo que o Pe. Augusto Magne dá: "Prende-se à raiz * qanth, alargamento da raiz *qamb, esquina, dobra, v. gr., de campus, camera, camurus" (op. cit., ibid). Frédéric Diez considera canthus de origem hispânica ou africana, apoiando-se em Quintiliano, vocábulo, depois, recebido pelos Romanos e divulgado pelos escritores (Grammaire des Langues Romanes "traduction par Auguste Brachet et Gaston Paris", Paris, 1874, vol. I, p. 85). Esta iberidade, em que Diez crê, é, pensamos, de boa natureza. O primeiro testemunho de canthus é de $\mathrm{Au}$ lus Persius Flaccus, que bem pode ter recebido o vocábulo, diretamente, de seus amigos Lucano e Séneca, ambos hispanos, ou indiretamente, de Lucílio, sua fonte de inspiração poética, para quem os falares de Hispânia seriam familiares, como se depreende de bracae (v. 409, ap. Adolf Schulten, Fontes... IV, pág. 94). por êle empregado, e, igualmente usado pelo espanhol Marcial (XI, 21). Quintiliano que muito admirou Pérsio: "Multum, et quidem verae gloriae Persius meruit". (op. cit., IV, 29) é outra fonte documental do têrmo, como, acima, vimos e com segura razāo, cremos, lhe dá origem africana ou hispânica.

É claro que, para entender-se a significação de canthus, de Marcial, é necessário compreender-se o trocadilho entre trochus "arco de ferro, usado como divertimento, a que eram apensas argolas bamboleantes que emitiam sons agudos, quando o brinquedo era jogado" e canthus "arco, aro, círculo de ferro, inteiriços, ou dividido em duas meias-luas, para proteger ou fortalecer as cambas das rodas dos carros", e, por extensão, "roda" e "carro".

Os dois versos: "Inducenda rota est: das nobis utile munus. | Iste trochus pueris, at mihi canthus erit.", podem traduzir-se do seguinte mo- 
do: "Uma roda deve ser fortalecida [por um arco, aro, círculo ou meiasluas]; dás-nos um presente útil. Este arco será [porém, útil] para as crianças; a mim (será útil) a roda (tôda) (o carro, enfim).

Ao que Marcial quere mesmo referir-se é ao canthus dos agricultores e carreiros de sua pátria. Um têrmo de audosismo do poeta. Leve recordação de muitas outras que êle, ausente, mimadamente, nutre, do Salo, de Bilbilis que sonha às suas margens, de tôda a Hispânia. $\mathrm{E}$ essa hispanidade heróica do vate é, ainda, hoje, passados milênios, a nossa hispanidade, pois conservamos, com o semanticismo de antanho, religiosamente, cantrelas, em Trás-osMontes e cantelas, no Minho, "carro de rodas" em que se encontra bem manifesta a base canth- cant-; e, ainda, cantadoira ou cantadoura "peça (duas) isoladas dos carros de bois". Também, o povo, de cultura linguística precaríssima, relaciona cantadoira ou cantadoura com o verbo cantar - cantare - canere. Mais para estranhar-se é que eminentes comentadores de Marcial tenham feito o mesmo, com respeito a canthus.

Em várias ediçōes de Marcial vê-se o termo ligado ao verbo cantare - canere "cantar", e, por essa razão, cantus, em vez de canthus, sentinco-se os comentadores, em sua maioria, apoiados na expressão "garrulus... annulus" do epigrama, a seguir (XIV, 169, v. 1), que desenvolve a idéia de trochus e esquece a de canthus: "Garrulus in laxo cur annulus orbe vagatur? | Cedat ut argutis obvia turba trochis".

Admirável é a interpretação dos "The Epigrams of Martial translated into English prose... Convent Garden, London, 1860", a melhor que vimos até hoje: "A wheel must be protected (with a tire). You make me a useful present. It will be a hoop to children, but to me a tire for my wheel".

Canthus vê-se em: M. Val. Martialis Epigrammata cum Notis Th. Farnabii, Amsterdami, 1644, com valiosíssimas notas, em latim; M. Val. Martialis ex Museo Petri Scriverii, Amstelodami, 1644; M. Val. Martialis Epigrammata, Demptis Obscenis, Addidit Annotationes et Interpretationem Josephus Juventius, Romae 1703, com notas preciosas, em latim; M. Valerii Martialis Epigrammatum Libri; ad Optimos Codices Recensiti et Castigati, Parisiis, 1754; M. V. Martialis Epigrammata ad Codices Parisinos accurate Recensita Variis Lectionibus, Notis Veteribus et Novis, Graeca Interdum Versione, Notitia Literaria et Indice Locupletissimo Illustraverunt Quinque Parisiensis Academiae Professores, Parisiis, 1825; com esta preciosa nota: "Quidam non bene cantus, per hoc intelligentes fragorem, strepitum, tinnitus trochi missi. Alii, ut nos canthus, ferrum nempe quo circum rota munitur" (vol. III, págs. 259 342); na edição "sous la direction de M. Nisard, Paris, 1843; Oeuvres Complètes de M. V. Martial, avec la traduction de MM. V. Verger, N. A. Dubois et J. Mangeart, Paris, Garnier; M. Valeri Martialis, Epigrammaton Libri, texte 
établi, traduit et annoté par Pierre Richard, Paris, Librairie Garnier Frères, 1931; com traduçāo pouco clara: "Un cerceau équipé pour le lancement, voilà (je t'en remercie) un présent utile: aux enfants le cerceau, à moi la garniture" (vol. II, p. 393).

Canthus vê-se em M. Val Martialis Epigrammaton Libri XIII interpretatibus Domitio Calderino, Georgioque Merula cum indice copiosissimo..., Venetiis 1552 , fl. 118; além do comentário "cantus ferrum significat, quo rotae vinciuntur...", com apoio em Quintiliano, êste outro "Alii cantus, id est harmoniam dixerunt quod placet..."; M. Val. Martialis Epigrammata Libri XV Lugduni, Apud Ant. Gryphium, 1588; M. Val. Martialis Epigrammaton Libri XII. Xeniorum Lib. I. Apophoretorum Libri I... Lugduni Batavorum, Ex Off. Platiniana", 1595; M. Valerii Martialis Epigrammaton Libri Omnes Novis Commentariis... a Matthaeo Radero, S. J. Ingolstadii, 1602, com notas muito longas, em latim; inclina-se a ligar a cantus, de cantare - canere; M. Valerii Martialis Epigrammatum Libros XV. Interpretatione et Notis Illustravit Vincentius Colesso. Parisiis, 1680 o comentador interpreta: "Impellenda est rota: nobis largiris donum utile. Pueri delectabuntur eo trocho, ego vero cantu"; e, a respeito de at mihi cantus, diz: "Nempe tinnitus ille trochi missi. Alii canthus, ferrum nempe quo circum rota munitur"; há ainda do mesmo comentador outra edição de Venetiis, 1739. 